\title{
Problemas en la frontera: retos migratorios en el Perú desde un enfoque interseccional de discapacidad
}

\author{
Trouble at the Border: Migration \\ Policy Challenges in Peru \\ from a Disability Perspective
}

Problèmes à la frontière: défis migratoires au Pérou liés à une approche intersectionnelle du handicap

\section{Renata Bregaglio Lazarte* Paula Camino Morgado**}

SUMARIO: I. Introducción. II. Contexto migratorio, vulnerabilidad e interseccionalidad. III. La necesaria incorporación del enfoque de discapacidad a la política migratoria. IV. Retos y lineamientos a partir del contexto peruano y comparado. V. Conclusiones. VI. Bibliografía.

* Pontificia Universidad Católica del Perú, Perú; ORCID ID: https: / / orcid.org/0000-00 03-4306-2511,renata.bregaglio@pucp.edu.pe.

** Pontificia Universidad Católica del Perú, Perú; ORCID ID: https: / / orcid.org/0000-00 02-0508-6005. 
RESUMEN: El presente artículo explora los retos que enfrenta el sistema migratorio peruano frente a la llegada masiva de refugiados con discapacidad. Utilizando el modelo social de la discapacidad como enfoque de análisis, las autores recalcan la importancia de hacer una lectura interseccional de la política migratoria. De esta manera, identifican, desde un enfoque de discapacidad, los principales problemas en la regulación migratoria peruana en relación con el reconocimiento de calidades migratorias, acceso a servicios públicos y recopilación de información estadísticas. Las autoras concluyen que la legislación peruana aún tiene una gran tarea pendiente de incorporar un enfoque transversal de discapacidad.

Palabras clave: discapacidad, política migratoria, refugio, interseccionalidad, migración masiva.

ABSTRACT: This article explores the challenges faced by the peruvian migration system in the face of the massive arrival of refugees with disabilities. Using the social model of disability as an analytical approach, the authors emphasize the importance of making an intersectional approach to migration policy. They identify, from a disability perspective, the main problems in peruvian migration regulation in relation to the recognition of migratory qualities, access to public services and compilation of statistical information. The authors conclude that peruvian legislation still has a great pending task of incorporating a transversal approach to disability.

Key words: disability, migration policy, refugees, intersectionality, mass migration.

RÉSUMÉ: Cet article explore les défis auxquels est confronté le système migratoire péruvien face à l'arrivée massive de réfugiés handicapés. En utilisant le modèle social du handicap comme approche analytique, les auteurs soulignent l'importance de faire une lecture intersectionnelle de la politique migratoire. De cette manière, elles identifient, du point de vue du handicap, les principaux problèmes de la régulation migratoire péruvienne en relation avec la reconnaissance des qualités migratoires, l'accès aux services publics et la compilation d'informations statistiques. Les auteurs concluent que la législation péruvienne a encore une grande tâche à accomplir pour intégrer une approche transversale du handicap.

Mots-clés: handicap, politique migratoire, réfugiés, intersectionnalité, migration de masse. 


\section{INTRODUCCIÓN}

De acuerdo con las últimas cifras de la Plataforma de Coordinación para Refugiados y Migrantes de Venezuela, al 3 de agosto de 2020, Perú ha recibido a 829,708 personas en situación migratoria regular. Y si bien no existen cifras oficiales sobre cuántas de estas personas se encuentran en situación de discapacidad, el Informe Semestral del Monitoreo de Protección de las Américas, del Alto Comisionado de Naciones Unidas para los Refugiados (ACNUR), identificó que entre agosto y septiembre del año anterior, 2019, la población con discapacidad representaba al 3\% del total de migrantes. ${ }^{1}$

Esta realidad genera múltiples retos desde un enfoque interseccional de discapacidad y migración. El presente artículo busca identificar dichos retos y plantear lineamientos para el diseño de políticas migratorias con enfoque con discapacidad, a la luz de lo dispuesto en la Convención sobre los Derechos de las Personas con Discapacidad, y del modelo social de la discapacidad.

El artículo se desarrolló a partir de tres grandes insumos. En primer lugar, se realizó una revisión, al igual que una sistematización de bibliografía, trabajos de campo y pronunciamientos de organizaciones internacionales sobre la materia. En segundo lugar, se enviaron solicitudes de acceso a la información pública a diversas estatales. Y en tercer lugar, se condujeron entrevistas semiestructuradas con actores relevantes y con usuarios de la Clínica Jurídica de Discapacidad de la Facultad de Derecho de la Pontificia Universidad Católica del Perú para conocer la realidad migratoria.

Por cuestiones de confidencialidad y en respeto del principio de no maleficencia en las investigaciones, se han omitido los nombres y datos que pudieran llevar a identificar a estas personas, y se ha optado por reseñarlos bajo el seudónimo de "informantes".

1 ACNUR, "Informe Semestral del Monitoreo de Protección en Perú", Lima, 2019, p. 4, disponible en: https: / / bit.ly/2WeFsIg. 


\section{CONTEXTO MIGRATORIO, VULNERABILIDAD \\ E INTERSECCIONALIDAD}

En los últimos años, Perú se ha perfilado como el primer país receptor de solicitantes de la condición de refugiado de personas venezolanas. ${ }^{2}$ Afrontar esta ola migratoria ha sido un reto significativo para las autoridades. El ministro de Relaciones Exteriores ha afirmado la necesidad de contar con apoyo internacional para afrontar la crisis migratoria, pues servicios como la atención en salud se encuentran desbordados. ${ }^{3}$ Este incremento masivo del movimiento migratorio ha implicado un desborde de recursos materiales, pero también ha revelado las falencias de la normativa y política migratoria peruana.

En efecto, la regulación migratoria se ha construido de manera ad hoc en respuesta a la crisis. Para sistematizar y simplificar estos desarrollos podemos identificar dos principales periodos en la regulación. ${ }^{4}$ En un primer periodo, desde el 31 de julio de 2016 hasta el 31 de julio de 2017 se permitió el ingreso a personas venezolanas a través de una categoría migratoria ad hoc - el permiso temporal de permanencia $(\mathrm{PTP})^{5}$. El PTP permitía a las personas migrantes ingresar a Perú, y regularizar su situación migratoria tras un año, sin que sea necesario presentar un pasaporte. ${ }^{6}$ En un segundo período, desde el 1 de noviembre de 2018 hasta la actualidad, las personas migrantes venezolanas ya no podían acceder al PTP. Sumado a ello, desde el 25 de agosto de 2018 ya se requiere la presentación del pasaporte a personas venezolanas en las fronteras, mediante Resolución de Superintendencia No. 000270-2018 de la Superin-

2 ACNUR, , "Perú", 2019, disponible en: https://www.acnur.org/peru.html.

3 "Cancillería: capacidad del Estado para atender el incremento de la migración venezolana ha sido sobrepasada”, El Comercio, 29 de octubre de 2019, disponible en: https://bit. ly/3fkM4fU.

4 Blouin, Cécile, "Entrevista sobre la migración venezolana y visa humanitaria”, Enfoque Derecho, 21 de junio 2019, disponible en: https: / / bit.ly/31wjE5w.

5 El PTP está regulado por los Decretos Supremos 002-2017-IN, publicado el 3 de enero de 2017; 023-2017-IN, publicado el 29 de julio de 2017; 001-2018-IN, publicado el 29 de julio de 2017, y 007-2018-IN, publicado el 19 de agosto de 2018.

6 Igualmente regulado en las normativas de la nota anterior. 
tendencia Nacional de Migraciones. ${ }^{7}$ En paralelo, el 12 de junio de 2019 se emitió la Resolución de la Superintendencia Nacional de Migraciones 117-2019, ${ }^{8}$ que estableció la posibilidad de ingresar al país con una visa humanitaria otorgada en el exterior. La Resolución en cuestión también estableció ciertas excepciones al requisito, sobre las cuales ahondaremos más adelante. Es así que, desde el 1 de noviembre de 2018 (momento en el que ya no era posible solicitar el PTP), las personas migrantes y refugiadas pueden ingresar al país, ya sea con un pasaporte vigente, como solicitantes de refugio o asilo; con una visa humanitaria; o bajo una de las excepciones establecidas en la Resolución de Superintendencia 117-2019.

Dentro de este grupo de migrantes, es natural que podamos encontrar a personas que se enfrentan a distintas situaciones de vulnerabilidad por motivos adicionales a su situación migratorio. Por ejemplo, un informe del ACNUR y la Organización Internacional para las Migraciones (OIM) identificó que de la población que ingresó a través de la frontera norte, 4.5\% tenían alguna enfermedad crónica o discapacidad, mientras que el 3\% que ingresaron a través de la frontera sur se encontraba en esta situación. ${ }^{9}$ De estos grupos, entre 73.3 y $80 \%$ requería tomar medicamentos diariamente. ${ }^{10}$ En la misma línea, el Informe Semestral del Monitoreo de Protección de las Américas del ACNUR señala que 3\% de los ingresantes entrevistados se encuentran en situación de discapacidad. ${ }^{11}$ De estas personas, 30 señalaron tener discapacidad física; 11 señalaron tener discapacidad mental o intelectual; 8 señalaron tener discapacidad visual, y 3 señalaron tener discapacidad en el habla. ${ }^{12}$ Sin embargo, solo $2 \%$ de migrantes y refugiados son remitidos a servicios especializados en discapacidad. ${ }^{13}$

Es importante detenernos en el especial impacto que tiene la discapacidad sobre las personas migrantes y refugiadas desde un enfoque interseccional. Adoptar un enfoque interseccional supone reconocer que

7 Aprobada el 24 de agosto de 2018, disponible en: https://bit.ly/2D5Irsq.

8 Publicada el 12 de junio de 2019, disponible en: https: / / bit.ly/35qe9MZ.

9 OIM \& ACNUR, "Monitoreo de flujo de población venezolana en el Perú”, DTM Ronda 5, Lima, 2019, p. 17, disponible en: https: / / bit.ly/3dx4Fnt.

10 Idem.

11 ACNUR, Monitero de Protección. Mayo-Junio 2019”, Lima, 2019, p. 4, disponible en: https: //data2.unhcr.org/en/documents/details/70520.

12 Idem.

13 Ibidem, p. 6. 
las formas de experimentar la discriminación varían en función de las características particulares de cada sujeto, a partir de un "sistema complejo de estructuras de opresión que son múltiples y simultáneas". ${ }^{14} \mathrm{El}$ enfoque permite identificar las consecuencias particulares que surgen de la combinación simultánea de diversos factores de vulnerabilidad en una persona. ${ }^{15}$

Las personas con discapacidad, al igual que el resto de personas, tienen derecho a migrar. Así lo establece el artículo 18.c de la Convención sobre los Derechos de Personas con Discapacidad (CDPD), que señala que tienen derecho a "salir de cualquier país, incluido el propio". Sin embargo, las personas migrantes y refugiadas con discapacidad enfrentan barreras específicas al momento de migrar que van más allá de las que enfrenta una persona migrante sin discapacidad. ${ }^{16}$ Entre ellas, por ejemplo, podemos pensar en la necesidades inmediatas que tendrán las personas con discapacidad (como acceder a atención médica), y la falta de accesibilidad de los procedimientos migratorios (por ejemplo, la dependencia en documentos escritos). Además, una barrera frecuente tiene que ver con las restricciones de salida o ingreso a un país en atención a la discapacidad mental. Para poder hacer frente a estas barreras, resulta necesario incorporar el enfoque de discapacidad a las políticas migratorias.

\section{LA NECESARIA INCORPORACIÓN DEL ENFOQUE DE DISCAPACIDAD A LA POLÍTICA MIGRATORIA}

Proteger adecuadamente a la población migrante con o son discapacidad, desde un enfoque del derecho internacional de los derechos humanos

14 Crenshaw, Kimberlé, "Mapping the Margins: Interseccionality, Identity Politcs and Violence Against Women of Color", en Crenshaw et al. (eds.), Critical Race Theory. The KeyWritings that Formed the Movement, Nueva York, The New Press, 1995, p. 140.

15 Aylward, Carol. "Intersectionality: Crossing the Theoretical and Praxis Divide". Journal of Critical Race Inquiry, vol. 1, núm. 1, 2010, p. 17, disponible en: https: / /doi.org/10.24908/ jcri.v1i1.3549.

16 Addaney, Michal et al, "'Legal Capacity of and Access to Justice for Refugees with Disabilities in Africa”, De Jure Law Journal, vol 52, núm. 1, 2019, p. 338, diponible en: http: / / www.scielo.org.za/scielo.php?script=sci_arttext\&pid=S2225-7160201900010002. 
(DIDH), supone reconocer la necesidad de un análisis interseccional. Solo de esta manera se podrá cumplir a cabalidad con el mandato de igualdad material e inclusión que rige el propio DIDH. Por ello, en este acápite abordaremos el modelo social de la discapacidad y las principales herramientas que este ofrece para responder a la situación de las personas migrantes.

\section{El modelo social de la discapacidad y su consagración normativa} en la Convención sobre los Derechos de las Personas con Discapacidad de Naciones Unidas

A lo largo del tiempo, la discapacidad se ha entendido desde distintos paradigmas o modelos. Siguiendo la clasificación de Palacios ${ }^{17}$, se pueden plantear tres grandes aproximaciones conceptuales a la discapacidad: 1) el modelo de la prescindencia; 2) el modelo médico o rehabilitador, y 3) el modelo social. ${ }^{18}$ Bajo el modelo de la prescindencia, las causas de la discapacidad son incomprensibles, se asocian a lo mágico o religioso. La persona con discapacidad no es considerada una persona útil en la sociedad, y tiene posibilidades casi nulas de inclusión. ${ }^{19}$ Bajo el modelo médico o rehabilitador, la persona con discapacidad es considerada una persona enferma. En esa línea, sus posibilidades de inclusión están condicionadas a su cura o normalización. Hasta hace unos años, las políticas migratorias para personas con discapacidad del propio ACNUR se regían por este modelo. ${ }^{20}$

Estas dos aproximaciones a la discapacidad se han visto modificadas por la introducción del modelo social de la discapacidad plasmado en la CDPD,

17 Palacios, Agustina, El modelo social de discapacidad. Orígenes, caracterización y plasmación en la Convención Internacional sobre los Derechos de las Personas con Discapacidad, Madrid, Cinca, 2008, p. 26.

18 Para otra clasificación de los abordajes, puede revisarse lo propuesto por Patricia Brogna "La representaciones de la discapacidad: la vigencia del pasado en las estructuras sociales presentes”, Visiones y revisiones de la discapacidad, México, Fondo de Cultura Económica, pp. 157-187.

19 Palacios, Agustina, op. cit., p. 39.

20 Crock, Mary et. al. "Where Disability and Displacement Intersect: Asylum Seekers and Refugees with Disabilities”, International Journal of Refugee Law, vol. 24, núm. 4, 2013, p. 757, disponible en: https: / / bit.ly/2L60wuc. 
que entró en vigor el 3 de mayo de 2008 y de la cual Perú es parte. A diferencia de los modelos anteriores, el modelo social entiende que la discapacidad no radica en la persona, sino que aparece ante la interacción de una deficiencia (de origen biológico) y una barrera (de índole social) que limita o restringe el ejercicio de derechos. ${ }^{21}$ El cambio de enfoque es fundamental, pues las posibilidades de inclusión de la persona con discapacidad no pasarán por los esfuerzos que esta realice, sino por las acciones de la sociedad y el entorno, orientadas a derriban las barreras que impiden ejercer derechos. Partiendo de esta premisa, el modelo social establece la necesidad de mitigar o superar las barreras que enfrentan las personas con discapacidad a través de medidas jurídicas y no jurídicas. ${ }^{22}$

Actualmente, tanto el DIDH como el ordenamiento jurídico peruano se rigen por el modelo social de la discapacidad. Así, la definición de discapacidad se consolida jurídicamente en el artículo 2o. de la CDPD y, en el caso peruano, en el artículo 2o. de la Ley 29973 - Ley General de la Persona con Discapacidad (LGPCD) de 2012-, emitida como parte de un proceso de adecuación normativa a dicho modelo. La adopción del modelo social a nivel jurídico supone un cambio paradigmático en la interacción de los Estados con las personas con discapacidad, que afecta incluso la respuesta de los Estados frente a la migración. Es en respuesta a la necesidad de derribar las barreras jurídicas y sociales que los Estados deben asegurar que las políticas migratorias respondan a las necesidades de migrantes con discapacidad, al margen de su cantidad, para cumplir cabalmente con sus obligaciones.

\section{Las tres claves para el enfoque de discapacidad desde}

el modelo social y su aplicación a las regulaciones

de migrantes con discapacidad

Para abordar la intersección entre las categorías "migrante" y "discapacidad”, es fundamental reconocer que no existe, aún, un estándar internacio-

21 Palacios, Agustina, op. cit.

22 Palacios, Agustina y Bariffi, Francisco, La discapacidad como una cuestión de derechos humanos. Una aproximación a la Convención Internacional sobre los Derechos de las Personas con Discapacidad, Madrid, Cinca, 2014, p. 19, disponible en: https: //bit.ly/2A16qKT. 
nal específico en cuánto a las implicancias del modelo social de la discapacidad sobre las normas en materia migratoria. Por el contrario, existen pocas normas y pronunciamientos que puedan orientar la adopción de medidas por parte del Estado. Ni los tratados internacionales en materia de migración y refugio hacen referencia especial a las personas con discapacidad, ni la CDPD hace referencia expresa a la migración. ${ }^{23}$

Sin perjuicio de ello, es importante notar que el artículo 11 de la CDPD sí establece una obligación de adoptar las medidas necesarias para garantizar la seguridad y protección de personas con discapacidad en contextos de riesgo y/o emergencias humanitarias. A partir de una interpretación literal y contextual de esta norma, podemos incluir situaciones de migración masiva dentro del supuesto de emergencias humanitarias. ${ }^{24}$ Así, este artículo resultaría aplicable a la situación de migrantes con discapacidad en Perú.

La expresión "todas las medidas necesarias" del artículo 11 de la CDPD no tiene un contenido específico. Resulta importante, entonces, detenerse sobre el cruce entre las categorías de migración y discapacidad para delimitar el contenido de las obligaciones que tendrían los Estados, como Perú, en situaciones como esta. Para ello, es importante tener presente tres grandes medidas que plantea la CDPD para asegurar el disfrute derechos de las personas con discapacidad en una sociedad: i) accesibilidad; ii) ajustes razonables, y iii) reconocimiento de capacidad jurídica. ${ }^{25}$

De acuerdo con el artículo 9o. de la CDPD, la accesibilidad está referida a las "medidas pertinentes para asegurar el acceso de las personas con discapacidad, en igualdad de condiciones con las demás, al entorno físico, el transporte, la información y las comunicaciones... a otros servicios e instalaciones abiertos al público o de uso público”. ${ }^{26}$ Por tanto, se refieren a adaptaciones de dichos entorno, que deben estar disponibles para el uso de toda persona con discapacidad sin que sea necesario solicitarlas. La accesibilidad se garantiza, por ejemplo, asegurando la distribución de información migratoria disponible en braille o audiotexto.

23 Addaney, Michal et al., op. cit., p. 337.

24 Addaney, Michal et al., op. cit., p. 341.

25 Bregaglio, Renata. "El principio de no discriminación por motivo de discapacidad", en Bregaglio, Renata y Salmón, Elizabeth (eds.), Nueve conceptos clave para entender la Convención sobre los Derechos de las Personas con Discapacidad, Lima, IDEHPUCP, 2014, p. 87.

26 En el caso peruano las definiciones en la LGPCD (artículo 15) y su Reglamento (artículo 3o, inciso 1) son esencialmente similares. 
Por otro lado, de acuerdo con el artículo 2o. de la CDPD, los ajustes razonables son "las modificaciones y adaptaciones necesarias y adecuadas que no impongan una carga desproporcionada o indebida, cuando se requieran en un caso particular, para garantizar a las personas con discapacidad el goce o ejercicio, en igualdad de condiciones con las demás, de todos los derechos humanos y libertades fundamentales". ${ }^{27}$ Estas medidas también se refieren a adaptaciones del entorno (incluso un entorno más amplio que el de la accesibilidad), pero tienen la particularidad de que son medidas ad hoc. Por tanto, se realizan ex post y responden a casos particulares. ${ }^{28}$ Por ejemplo, podría resultar necesario en el caso específico de una persona con discapacidad mental, sostener entrevistas más largas que el promedio para decidir conceder o no determinado estatus migratorio. Volveremos a estos ejemplos en al acápite IV del presente artículo.

Finalmente, el reconocimiento de la capacidad jurídica se encuentra en el artículo 12 de la CDPD. De acuerdo con dicho artículo, todas las personas con discapacidad deben tener la capacidad de tomar sus propias decisiones a partir de su voluntad expresada. Esto implica, entre otras cuestiones, que los ordenamientos civiles de los Estados partes dejen de catalogar a la personas con discapacidad como incapaces. El artículo 12.3 del mismo ordenamiento establece que en el ejercicio de esta capacidad jurídica, las personas con discapacidad podrían libremente designar "apoyos para la toma de decisiones". Estos no son curadores, sino mecanismos para facilitar la voluntad frente a una decisión de contenido jurídico.

Esto es particularmente relevante en el contexto peruano, pues en septiembre de 2018 se publicó el Decreto Legislativo 1384, que modificó el Código Civil en materia de capacidad jurídica de personas con discapacidad. En virtud de esta modificación, todas las personas con discapacidad tienen plena capacidad jurídica. En el caso de la práctica migratoria, no podría negarse el acceso a trámites migratorios y menos aún, restringir la libertad de una persona migrante con discapacidad.

En consecuencia, si bien en el marco del artículo 11 de la CDPD existe cierta libertad de los Estados al determinar las medidas que adoptarán para

27 La misma definición se encuentra en el Reglamento de la LGPCD (artículo 3.2).

28 Constantino Caycho, Renato y Galicia Vidal, Saulo, "La configuración de los ajustes razonables en el ámbito laboral peruano: definiciones, omisiones y propuestas", Anuario de Investigación del CICAJ 2013-2014,2015, p. 265, disponible en: https: / /bit.ly/2 WbiodI. 
atender a migrantes y refugiados con discapacidad, estas deberán realizarse tomando en cuenta las medidas de accesibilidad, ajustes razonables y reconocimiento de capacidad jurídica. En esta línea, el Comité sobre lod Derechos de las Personas con Discapacidad (en adelante, Comité) ha formulado observaciones sobre la situación de refugiados y migrantes con discapacidad a los Estados partes bajo el amparo del artículo 11 de la CDPD. En sus observaciones, el Comité, si bien no ha determinado una manera única de satisfacer esta obligación, sí ha planteado medidas que responden a los tres elementos del enfoque.

Así, ha señalado a los Estados que deben tomar medidas diversas, partiendo de la infraestructura existente para atender a situaciones de emergencia. Entre otras medidas, el Comité ha recomendado la adopción de planes y estrategias nacionales integrales de protección a personas con discapacidad; la mejora de programas y políticas de refugio para personas con discapacidad; la mejora de accesibilidad, y la adopción de otras medidas. Podemos ver algunas de sus recomendaciones formuladas en la siguiente tabla:

\section{TABLA 1. RECOMENDACIONES FORMULADAS POR EL COMITÉ EN MATERIA DE REFUGIO Y MIGRACIÓN}

\begin{tabular}{|c|c|l|}
\hline Estado & Año & \multicolumn{1}{|c|}{ Recomendación } \\
\hline Kenia & 2015 & $\begin{array}{l}\text { Adoptar una estrategia de riesgo y emergencia que integre } \\
\text { una perspectiva de discapacidad. }\end{array}$ \\
\hline Portugal & 2016 & $\begin{array}{l}\text { Mejorar las políticas y programas de atención a migrantes, } \\
\text { solicitantes de asilo y de refugio con discapacidad. }\end{array}$ \\
\hline Uganda & 2016 & $\begin{array}{l}\text { Aprobar un plan nacional para asegurar la accesibilidad, in- } \\
\text { clusión y protección de personas con en situaciones de ries- } \\
\text { go y emergencias humanitarias. Proporcionar información } \\
\text { accesible. }\end{array}$ \\
\hline Italia & 2016 & $\begin{array}{l}\text { Asegurar que las personas con discapacidad que ingresan } \\
\text { al país accedan a servicios e instalaciones, y que las per- } \\
\text { sonas con discapacidad psicosocial reciban apoyo y reha- } \\
\text { bilitación. }\end{array}$ \\
\hline Jordania & 2017 & $\begin{array}{l}\text { Adoptar una estrategia integral, protocolos de emergencia } \\
\text { y reducción del riesgo de desastre que sean accesibles. }\end{array}$ \\
\hline
\end{tabular}




\begin{tabular}{|c|c|l|}
\hline Estado & Año & \multicolumn{1}{c|}{ Recomendación } \\
\hline Canadá & 2017 & $\begin{array}{l}\text { Realizar un estudio sobre el acceso de personas asiladas y } \\
\text { refugiadas a los derechos reconocidos en la CDPD. Asegu- } \\
\text { rar la provisión de información accesible para solicitantes } \\
\text { de asilo y refugio. Establecer programas de capacitación en } \\
\text { materia de discapacidad para funcionarios de cooperación y } \\
\text { asistencia internacional. }\end{array}$ \\
\hline Algeria & 2018 & $\begin{array}{l}\text { Adoptar medidas para supervisar la situación de las perso- } \\
\text { nas con discapacidad en campamentos de refugiados y des- } \\
\text { plazados internos. Garantizar el acceso a todos los servicios } \\
\text { disponibles en dichos campamentos. }\end{array}$ \\
\hline
\end{tabular}

FUENTE: Elaboración propia, adaptado de Camino, Paula, Riesgos invisibilizados: la necesidad de una directiva de atención a refugiados y refugiadas con discapacidad, tesina para optar por el grado Bachiller en Derecho, Lima, PUCP, 2020, p. 24, disponible en: https: / / bit.ly/2WCQIgH.

Adicionalmente, el Comité se ha referido a las personas migrantes con discapacidad fuera del contexto del artículo 11. En 2019, el Comité recomendó a Turquía adoptar un protocolo de provisión de ajustes razonables en los procedimientos migratorios y de determinación del estatus de refugiado, así como asegurar que las políticas públicas atiendan a las necesidades de migrantes y refugiados con discapacidad. ${ }^{29}$ En el mismo sentido, también ha recomendado a Estados, Arabia Saudita, Noruega, Chipre, Alemania, Ruanda y Reino Unido que aseguren que los migrantes y refugiados con discapacidad sean considerados en las políticas y programas estatales, de manera puedan acceder a los servicios necesarios para ejercer los derechos reconocidos en la CDPD. ${ }^{30}$

Es importante tomar en cuenta también los pronunciamientos por el Comité de Trabajadores Migrantes de Naciones Unidas. Aunque no se ha

29 Comité, Observaciones finales a Turquía, CRPD/C/TUR/CO/1, 2019, párr. 39.

30 Comité, Observaciones finales a Arabia Saudita, CRPD/C/SAU/CO/1, 2019, párr. 34; Observaciones finales a Noruega, CRPD/C/NOR/CO/1, 2019, párr. 12; Observaciones finales a Chipre, CRPD/C/CYP/CO/1, 2017, párr. 16; Observaciones finales a Alemania, CRPD/C/DEU/CO/1, 2015, párrs. 16, 48; Observaciones finales a Ruanda, CRPD/C/ RWA/CO/1, 2019, párr. 30; Observaciones finales al Reino Unido, CRPD/C/GBR/CO/1, 2017, párr. 31. 
pronunciado de manera directa respecto de contextos de emergencia, ha destacado de manera amplia la necesidad de remover cláusulas discriminatorias de las legislaciones y políticas migratorias de los países miembros en su Observación General 3, ${ }^{31}$ así como sus observaciones finales a Honduras, Belice, Sri Lanka y México. ${ }^{32}$

En ese sentido, tratar con personas migrantes y refugiadas con discapacidad exige a los Estados adoptar medidas específicas que respondan a la particular situación de vulnerabilidad en la que se encuentran. Estas medidas, además, deben alinearse al modelo social de la discapacidad actualmente vigente en el derecho internacional de los derechos humanos. Esto implica, entonces, implementar medidas de accesibilidad, ajustes razonables y reconocer la capacidad jurídica en distintos aspectos del proceso migratorio, como detallaremos en las siguientes secciones.

\section{RETOS Y LINEAMIENTOS A PARTIR DEL CONTEXTO PERUANO Y COMPARADO}

Como hemos señalado al inicio, la situación migratoria que ha enfrentado Perú en los últimos años ha generado diversos retos a nivel jurídico-político. En parte, esta situación puede ser atribuida a la falta de preparación institucional frente a una migración masiva, que se acentúa si pensamos en el caso de personas con discapacidad. En el ordenamiento jurídico peruano ni la LGPD, ni la Ley No 27891 — Ley General del Refugiado- ni su Reglamento, contemplan disposiciones específicas sobre migración y discapacidad. Solo el Decreto Legislativo 1350 —Decreto Legislativo de Migraciones - hace referencia a las personas con discapacidad como parte del

31 Comité de Trabajadores Migrantes de Naciones Unidas, Observación general conjunta núm. 3 (2017) del Comité de Protección de los Derechos de Todos los Trabajadores Migratorios y de sus Familiares, y núm. 22 (2017) del Comité de los Derechos del Niño sobre los principios generales relativos a los derechos humanos de los niños en el contexto de la migración internacional, $\mathrm{CMW} / \mathrm{C} / \mathrm{GC} / 3-\mathrm{CRC} / \mathrm{C} / \mathrm{GC} / 22$, 2017, párrs. 21-25.

32 Comité de Trabajadores Migrantes, Observaciones finales a Honduras, CMW/C/ $\mathrm{HND} / \mathrm{CO} / 1$, 2016; Observaciones finales a Belice, CMW/C/BLZ/CO/1, 2014; Observaciones finales a Sri Lanka, CMW/C/LKA/CO/2, 2016; Observaciones finales a México, $\mathrm{CMW} / \mathrm{C} / \mathrm{MEX} / \mathrm{CO} / 3,2017$. 
colectivo de "personas extranjeras en situación de vulnerabilidad". ${ }^{33}$ Este Decreto, además, considera a los/as hijos/as con discapacidad mayores de edad que no puedan proveer su propia subsistencia como miembros de la unidad migratoria familiar. ${ }^{34}$

Si bien el Decreto en cuestión no establece regulaciones específicas para este colectivo, sí establece, en su artículo 11, que las autoridades competentes en materia migratoria deben poner en conocimiento de las demás autoridades competentes las situaciones de vulnerabilidad, a fin de que estas adopten las medidas de protección necesarias. Adicionalmente, la norma dispone que corresponde a las autoridades en materia migratoria adoptar los criterios necesarios para prestar asistencia a personas en situación de vulnerabilidad. A la fecha, no se han adoptado regulaciones complementarias para materializar este mandato en un texto unificado. Existen, empero, resoluciones administrativas (como la Resolución de la Superintendencia Nacional de Migraciones 117-2019) y políticas institucionales que se alinean a este artículo (como la emisión del carnet de vulnerabilidad), que serán analizadas en los siguientes párrafos.

Frente a este panorama, no es sorprendente que las personas migrantes y refugiadas con discapacidad se enfrenten a situaciones adversas al llegar a Perú. A continuación, se realiza una sistematización de dichos retos, a partir de la experiencia de la migración venezolana, y se proponen lineamientos para dar una respuesta adecuada desde el modelo social de la discapacidad. Cabe señalar que, a la fecha, no se cuenta con información detallada sobre la situación de personas migrantes y refugiadas con discapacidad en el país. Por ello, los problemas han sido reconstruidos, en buena cuenta, a partir de relatos de migrantes, así como de funcionarios públicos y de cooperación internacional en Perú.

33 Artículo 11 del Decreto Legislativo 1350, Decreto Legislativo de Migraciones. De manera complementaria, el artículo 226 del Reglamento establece que "son personas en situación de vulnerabilidad aquellas personas extranjeras que se encuentran en situación de desprotección o riesgo de no acceder al ejercicio pleno de sus derechos fundamentales en nuestro país”. El artículo 227 establece que son supuestos de vulnerabilidad, entre otros, el ser persona con discapacidad o con grave enfermedad. Decreto Supremo 007-2017-IN, Decreto Supremo que aprueba el Reglamento del Decreto Legislativo N ${ }^{\circ} 1350$, Decreto Legislativo de Migraciones y aprueban nuevas calidades migratorias, publicado el 27 de marzo de 2017.

34 Artículo 38 del Decreto Legislativo 1350, Decreto Legislativo de Migraciones. 


\section{Solicitantes de refugio}

Actualmente, las personas de nacionalidad venezolana que llegan a la frontera peruana no cuentan con la posibilidad de ingresar sin visa previa. En ese sentido, muchas personas optan por formular solicitudes de reconocimiento del estatus de refugiado/a. En Perú, de conformidad con el Reglamento de la Ley General del Refugiado, el procedimiento de reconocimiento del estatus de refugiado tiene tres etapas: una etapa escrita (solicitud), una etapa oral (entrevista) y una etapa de evaluación, todas a cargo de la Comisión Especial de Refugiados (CEPR) del Ministerio de Relaciones Exteriores. Ya en este procedimiento regular, las personas solicitantes de refugio en situación de discapacidad enfrentan una serie de barreras.

Una primera barrera surge en relación con la accesibilidad de la información sobre el procedimiento. La obligación de adoptar medidas de accesibilidad, consagrada en el artículo 9o. de la CDPD y 15 de la LGPD, supone que el Estado debe tomar medidas previas para asegurar que las personas con discapacidad puedan acceder a dicha información, así como elegir la forma más adecuada de comunicarse. En línea con el artículo 21 de la LGPD, las entidades públicas deben garantizar la accesibilidad y libertad de elección de las personas con discapacidad en la comunicación. Esta obligación se puede satisfacer de diversas maneras. En el caso de personas con discapacidad visual, se pueden proveer los formularios en braille, mientras que en el caso de personas con discapacidad intelectual se podrá proveer documentos de lectura fácil. No obstante, estos no son los únicos formatos de comunicación accesibles reconocidos por la legislación peruana. Por ello, es necesario proveer formatos de comunicación táctil, macrotipos, visualización de textos, dispositivos multimedia, sistemas auditivos, medios de voz digitalizada y otros modos o medios aumentativos o alternativos de la comunicación.

En Perú, sin embargo, la información sobre el trámite de solicitudes de refugio se difunde por vía escrita y en páginas web que no pueden ser leídas por los software lectores de pantalla. Por ello, aún existe una tarea pendiente del Estado en cuanto a la accesibilidad de la información para formular una solicitud y navegar el procedimiento de reconocimiento. ${ }^{35}$ De lo contrario,

35 ACNUR, Conclusión general sobre la protección internacional No. 110, 2010; Comité sobre los Derechos de las Personas con Discapacidad, Observaciones finales a Uganda, 
las personas con discapacidades visuales e intelectuales se encontrarán en situación de desventaja frente a la posibilidad de ser reconocidas como refugiados en el país.

Un segundo problema surge en relación con la adopción de medidas de accesibilidad y ajuste razonable a lo largo del procedimiento de solicitud. Siguiendo las recomendaciones del ACNUR y del Comité, los Estados deberían contar con solicitudes y entrevistas que sean plenamente accesibles. ${ }^{36}$ Esto implica, por ejemplo, que desde un inicio se debería asegurar que la persona con discapacidad pueda llenar su propia solicitud de refugio en el lenguaje que les resulte accesible. En efecto, el artículo 19 del Reglamento de la Ley General del Refugiado establece que cuando una persona no pueda llenar una solicitud de refugio, se le deben otorgar "las facilidades para continuar con el trámite”. Esta norma, leída desde una perspectiva de discapacidad, por supuesto, nos lleva a entender que se deben adoptar las medidas de accesibilidad ya mencionadas para facilitar el llenado de una solicitud de refugio. En la misma línea, y de conformidad con el artículo 23 del Reglamento de la Ley General del Refugiado, las entrevistas deberían contar con un intérprete de lengua de señas cuando ello resulte necesario.

Además, cuando las medidas de accesibilidad no resulten suficientes, deberán aplicarse ajustes razonables que permitan responder a la diversidad de migrantes que ingresan a Perú. ${ }^{37}$ Por ejemplo, cuando las entrevistas se realizan a personas con discapacidad intelectual o psicosocial, estas se deben llevar a cabo en lenguaje sencillo, de resultar necesario. Y dado que no es posible prever los ajustes razonables que necesitará cada solicitante de refugio, es importante que exista un mecanismo que permita solicitarlos de manera previa a la entrevista o evaluación.

Dado que no es posible prever los ajustes razonables que necesitará cada solicitante de refugio, es importante que exista un mecanismo que permita

CRPD/C/UGA/CO/1, 2016, párr. 21; ACNUR e Inter-Parliamentary Union, A Guide to International Refugee Protection and Building State Asylum Systems. Handbook for Parliamentarians $N^{\circ}$ 27, Ginebra, Inter-Parliamentary Union-United Nations High Commissioner for Refugees, 2017, p. 181.

36 ACNUR, Conclusión general sobre la protección internacional No. 110, 2010, literal j; Comité sobre los Derechos de las Personas con Discapacidad, 2017, Observaciones finales a Canadá. CRPD/C/TUR/CO/1, párr. 16.

37 ACNUR e Inter-Parliamentary Union, op. cit., p. 110. 
solicitarlos de manera previa a la entrevista o evaluación. Sin embargo, el sistema web de registro de solicitudes y citas utilizado por la CEPR no permite registrar la discapacidad, ni registrar solicitudes de ajustes razonables o medidas de accesibilidad. ${ }^{38}$ Más aún, en respuesta a la solicitud de acceso a la información pública núm. 473-2019 formulada por las autoras, el Ministerio de Relaciones Exteriores señaló que no existe un protocolo u otro documento que regule la adopción de ajustes razonables en la entrevista de calificación.

Por lo explicado, es claro que no se adoptan medidas de accesibilidad ni ajustes razonables con anticipación en el procedimiento de determinación del estatus de refugiado. A lo sumo, las personas pueden solicitar las medidas necesarias al momento de la entrevista, pero conseguir implementarlas resultará difícil. Según señala el Ministerio de Relaciones Exteriores, se procura derivar los casos de personas con discapacidad a un analista psicólogo de profesión que forma parte de la CEPR. ${ }^{39}$ Sin embargo, estas medidas ad hoc pueden resultar en retrasos aún mayores al momento de procesar las solicitudes, que resultan sumamente perjudiciales en los casos de personas con discapacidad.

Un tercer problema surge en la etapa de evaluación. En esta, los/as funcionarios/as públicos/as deben verificar la concurrencia de los requisitos normativos para el reconocimiento del estatus de refugiado/a. En torno a esta evaluación, hemos tomado conocimiento de diferentes versiones de lo que ocurre en la frontera. Ciertas fuentes señalan que el módulo de cancillería ubicado en el Centro Binacional de Atención en Frontera (CEBAF) de la frontera realiza un examen preliminar a efectos de determinar si hay persecución o no. ${ }^{40}$ Otra fuente señala que al llegar a la frontera, las personas pueden formular una solicitud de refugio en el CEBAF. En esos casos, tienen una entrevista en el lugar, los datos se envían a Lima, y se emite una decisión. ${ }^{41}$ En respuesta a la solicitud de acceso a la información pública núm. 473-2019 formulada por las autoras, el Ministerio de Relaciones Exteriores señala que el procedimiento de calificación se inicia con una entrevista en las oficinas de la Secretaría

38 El contenido del formulario se puede visualizar en: https: / citasrefugiados.gob.pe/.

39 Respuesta remitida a la solicitud de acceso a la información núm. 473-2019.

40 Información proporcionada de manera confidencial por el informante 1.

41 Información proporcionada de manera confidencial por el informante 2. 
Ejecutiva de la CEPR, que luego es evaluada a Lima. En todo caso, lo importante para es que al realizar esta evaluación, los funcionarios deberían incorporar un enfoque de discapacidad.

Esto presenta algunos retos al evaluar el temor fundado de persecución de una persona con discapacidad psicosocial. El primero de ellos tiene que ver con la falta de credibilidad respecto de aquellos hechos que motivan su solicitud. El que la persona con discapacidad añada a su relato hechos poco verosímiles o inconsistentes lleva a que los funcionarios que evalúan su solicitud duden sobre la veracidad de estos. ${ }^{42}$ El segundo reto está en la necesidad de valorar la discapacidad de la persona solicitante al evaluar la solicitud de refugio. Verificar la existencia de un "temor fundado de persecución” tiene un componente objetivo, pero también un componente subjetivo. Este último, tradicionalmente, se evalúa en base a un parámetro de racionalidad. Tal parámetro, sin embargo, resulta inadecuado de cara a las solicitudes que presentan personas con discapacidad psicosocial. En esa línea, el ACNUR ya ha señalado que la evaluación del temor fundado es "inseparable de una evaluación de la personalidad del solicitante, ya que las reacciones psicológicas de diferentes individuos pueden no ser las mismas en condiciones idénticas" (traducción propia). ${ }^{43}$

Ante las dificultades que genera evaluar el temor fundado de persecución en casos como estos, se han ensayado diversas opciones. Por un lado, se propone evaluar el temor de los acompañantes de la persona con discapacidad, prescindiendo de la experiencia de la propia persona con discapacidad. Esta propuesta no resulta satisfactoria, pues contradice uno de los postulados fundamentales del modelo social —el reconocimiento de la autonomía. ${ }^{44}$ Por otro lado, el ACNUR propone la implementación de un análisis diferenciado, que acepte o bien un temor razonable o uno que parezca exagerado si es que, dadas las circunstancias, podría ser justificado. ${ }^{45}$ Esta última propuesta supone incorporar una opinión médica sobre la discapacidad, y

42 Información proporcionada de manera confidencial por el informante 3.

43 Texto original: "An evaluation of the subjective element is inseparable form an assessment of the personality of the applicant, since psychological reactions of different individuals may not be the same in identical conditions". ACNUR, Manual de procedimientos y criterios para determinar la condición de refugiado en virtud de la Convención de 1951 y el Protocolo de 1967 sobre el Estatuto de los Refugiados, Ginebra, ACNUR, 2019, p. 19.

44 Crock, Mary et al., op. cit., pp. 743 y 744.

45 ACNUR, Manual de Procedimientos..., cit., p. 19. 
dar mayor relevancia al elemento objetivo y la historia de vida del solicitante, para determinar la fundabilidad del temor alegado. ${ }^{46}$

En nuestra opinión, requerir un informe médico o psiquiátrico puede llevar a medicalizar la discapacidad, retornando a los fundamentos del modelo médico. Con ello se corre el riesgo de ubicar la discapacidad en la persona y, a partir de ello, proyectar conclusiones generalizables a todas las personas en la misma situación. Las autoras no niegan que una persona con discapacidad psicosocial pueda tener percepciones falsas de la realidad. No obstante, esto no ocurrirá en todos los casos ni con todas las personas que tengan un mismo diagnóstico. Solicitar un diagnóstico como parte de la evaluación podría llevar a asumir que siempre la persona con discapacidad estará narrando hechos falsos, y ciertamente un personal médico no podría diferenciar los hechos verdaderos de los falsos. Ello sin contar la dificultad de hallar personal médico calificado para dar ese diagnóstico en los puntos de frontera, especialmente si tenemos en cuenta que en 2019 Perú solo contaba con 1,082 psiquiatras $^{47}$, y la dificultad de generar diagnósticos psiquiátricos en un lapso corto de tiempo.

En ese sentido, proponemos (en línea con lo que plantea el ACNUR) que ante los indicios de estar en presencia de una persona con discapacidad psicosocial se realice un análisis diferenciado del temor fundado a cargo de la CEPR, pero tomando en consideración algunas garantías específicas: i) prescindencia de la evaluación médica (si la persona cuenta con un documento que acredite discapacidad, este solo deberá servir para confirmar los indicios que llevan a la aplicación de estas garantías, pero no para determinar la veracidad o falsedad de sus narraciones); ii) realizar (a modo de ajuste razonable) una entrevista más larga, o incluso varias entrevistas a lo largo de algunos días; iii) evaluar la necesidad de que en la entrevista se encuentre presente también algún familiar o persona de confianza para la persona con discapacidad, y iv) si el relato resulta confuso o inverosímil, dar mayor valoración a los elementos contextuales (si una persona dice que una "bruja" la persigue, antes que dudar de la persecución habrá que indagar si el personaje "bruja" podría representar a alguien).

46 Ibidem, párr. 208-212.

47 Treneman, Alvaro, “¡Alarmante! En el Perú solo existen 1082 psiquiatras de los cuales solo cinco se especializan en adicciones”, Perú 21, 20 de noviembre de 2019, disponible en: https: / / bit.ly/3dCZwu7. 
Tomando estas dificultades en cuenta, un examen previo como el que supuestamente se estaría realizando en la frontera podría generar un impacto perjudicial en las solicitudes de personas con discapacidad psicosocial. El ACNUR ya se ha pronunciado sobre el uso de mecanismos de screening o preexamen, en el marco del "Plan de Acción de los 10 Puntos”, señalando claramente que la información recabada en esta primera preevaluación no debe ser determinante en la evaluación de la condición de refugio. ${ }^{48}$ No obstante, es claro que estos exámenes previos, por su naturaleza, tendrán la finalidad de ser un mecanismo rápido de filtro de solicitantes. La rapidez no resulta nunca adecuada para entrevistar a una persona con discapacidad. En todo caso, ante indicios de discapacidad psicosocial, lo más adecuado sería no filtrar a la persona en el preexamen y permitirle acceder al trámite de entrevista regular con las garantías aquí propuestas.

\section{Solicitantes de otras categorías migratorias en contextos de emergencia}

Las personas migrantes con discapacidad también pueden acceder a otras calidades migratorias contempladas en la normativa peruana. Nos enfocaremos en dos de ellas que resultan particulares: la calidad migratoria que llamaremos ad hoc, y la residencia por razones humanitarias. En relación con la primera calidad migratoria, el artículo 11.2 del Decreto Legislativo 1350 establece que la Superintendencia Nacional de Migraciones y el Ministerio de Relaciones Exteriores pueden emitir documentos y/o permisos de permanencia temporal o residencia pertinentes para asistir a personas en situación de vulnerabilidad, entre las cuales se encuentran las personas con discapacidad. En virtud de este artículo, del Oficio del Ministerio de Relaciones Exteriores (DGC) N² 2-10-E/ 1081 de mayo de 2019, y la Resolución de la Superintendencia Nacional de Migraciones 117-2019, se ha implementado una calidad migratoria ad hoc por situación de vulnerabilidad desde junio de 2019.

48 ACNUR, "Mechanisms for Screening and Referral, The 10 Point Plan in Action", 2016, p. 114, disponible en: https: / /bit.ly/3dpk6xD. 
La resolución referida dispone que en ciertos casos,${ }^{49}$ incluyendo casos de mayores de edad “en situación de extrema vulnerabilidad”, sólo se exigirá la presentación de una cédula de identidad para acceder al país. Hemos tomado conocimiento de que se ha utilizado esta cláusula para facilitar el ingreso de migrantes con discapacidad. ${ }^{50} \mathrm{Si}$ bien esto puede considerarse positivo de cara a otorgar la protección necesaria a las personas con discapacidad, algunas han reportado que las autoridades peruanas de frontera solicitan un informe médico emitido por un médico ecuatoriano o peruano para acreditar la discapacidad. ${ }^{51}$

Cuando esto ocurre, el acceso a la visa humanitaria resulta inviable, pues la persona con discapacidad no tiene posibilidad de acceder a un certificado médico en la frontera y, como se verá más adelante, para obtener este certificado se requiere contar con Documento Nacional de Identidad o Carnet de Extranjería. Aún si la persona tuviese la posibilidad de obtener un certificado de discapacidad, este trámite puede demorar hasta varios meses. En esa medida, la persona con discapacidad a quien se solicite dicho certificado para acceder a la calidad migratoria ad hoc resultará impedida de ingresar al país. En nuestra opinión, solo se justificaría solicitar este documento no siendo visible la discapacidad, o si la persona no tuviese un documento de su propio país que la acredite. En su lugar, podría aceptarse cualquiera de los siguientes documentos: certificado o carnet de discapacidad del país de origen, informe médico de un centro público o privado, o certificado de discapacidad peruano.

En relación con la segunda calidad migratoria, el artículo 29.2.k del Decreto Legislativo 1350 establece que la Superintendencia de Migraciones puede emitir un "permiso de residencia en su versión humanitaria". ${ }^{52}$ Esta categoría migratoria opera para aquellas personas que, sin reunir las

49 La Resolución precisa los siguientes supuestos: i) menores de edad en tránsito hacia el Perú para reunirse con sus padres que no cuenten con cédula de identidad o pasaporte sino únicamente partida de nacimiento; ii) mayores de edad en tránsito hacia el Perú para reunirse con su núcleo familiar residente en Perú; iii) mayores de edad en situación de extrema vulnerabilidad en tránsito hacia el Perú; iv) mujeres embarazadas en situación de extrema vulnerabilidad en tránsito hacia el Perú, y v) adultos mayores, de más de 60 años, en tránsito hacia el Perú.

50 Información proporcionada de manera confidencial por el informante 1.

51 Idem.

52 El texto del artículo citado señala lo siguiente: "Artículo 29.2. Residencia: 
condiciones necesarias para acceder al reconocimiento como refugiadas, se encuentran en situaciones de gran vulnerabilidad o provienen de países en situaciones excepcionales de crisis humanitaria. La mencionada Resolución 117-2019 estableció una serie de requisitos para acceder a esta residencia. Asimismo, la misma Superintendencia emitió los "Lineamientos para la emisión del Carnet de Extranjería a personas de nacionalidad venezolana con calidad migratoria de residente humanitario".

Dichos lineamientos establecen en su artículo 5.1.2.b que si se trata de una persona mayor de edad "con discapacidad absoluta que le impida manifestar su voluntad de manera indubitable”, se deberá presentar un "documento emitido por autoridad competente que acredite curatela o nombramiento de figura legalmente afín”. Este requisito a todas luces resulta contrario al mandato de reconocimiento de capacidad jurídica previsto en la artículo 12 de la CDPD y desconoce la reforma del Código Civil de 2018. Además, aun asumiendo la validez de la restricción de capacidad jurídica, resultaría incomprensible que se condicione la emisión de un documento de identidad a la adopción de medidas de incapacitación.

En una línea similar, en octubre de 2020 se publicó el Decreto Supremo No. 010-2020-IN, que aprueba medidas especiales, excepcionales y temporales para regularizar la situación migratoria de extranjeros y extranjeras. Dicha norma en su artículo 7o. señala que en el caso de "personas extranjeras mayores de 18 años con discapacidad permanente, que no puedan expresar su voluntad de manera indubitable”, deberá presentarse, entre otros requisitos, una "copia simple del documento que acredite la representación legal de acuerdo al Código Civil”.

A diferencia de la anterior, esta norma no tiene como supuestos de hecho el estar bajo curatela, sino el no poder manifestar voluntad. En este supues-

k. Humanitaria. Para el extranjero que encontrándose en territorio nacional y sin reunir los requisitos para acceder a la condición de asilado o refugiado, se encuentre en situación de gran vulnerabilidad o peligro de vida en caso de abandono del territorio peruano o para quien requiere protección en atención a una grave amenaza o acto de violación o afectación de sus derechos fundamentales. Del mismo modo, será aplicable para los solicitantes de refugio y asilo o para quienes hayan migrado por motivos de desastres naturales y medioambientales; o para quienes han sido víctima de trata o tráfico de personas; o para las niñas, niños y adolescentes no acompañados; o para apátridas. También se aplica para personas que se encuentren fuera del territorio nacional en situaciones excepcionales de crisis humanitaria reconocida internacionalmente, que soliciten venir al Perú y obtener protección. Permite realizar actividades lucrativas de manera subordinada, autónoma o por cuenta propia”. 
to, el Código Civil reformado establece la posibilidad de designar apoyos excepcionales para materializar un acto jurídico que es necesario para la persona con discapacidad. En nuestra opinión, la norma buscaría únicamente acreditar que la persona con discapacidad no ha sido traída al país en contra de su voluntad (o sin conocerla), y por ello podría entenderse como necesario formalizar que una tercera persona actúe como su apoyo para la regularización migratoria. Sin embargo, sería deseable que la norma se adecue a la terminología del Código Civil e hiciera referencia a este. Ello haría que en lugar de hablar de "representación legal" se hable de "apoyos", y que el estándar de no manifestación de la voluntad sea el utilizado en el artículo 659-E del Código (y no dejar a interpretación de la autoridad migratoria cómo entender este requisito). Asimismo, se debería asumir que frente a un escenario en donde no exista formalización previa, la solución no puede ser la expulsión de la persona con discapacidad, sino justamente el buscar esta formalización con las autoridades nacionales. Pero incluso esta interpretación resulta cuestionable, tanto desde el punto de vista convencional como del práctico. En todo caso, lo cierto es que al dejarse un amplio margen a los operadores de primera línea, es probable que sea interpretada de manera tal que se exija un documento que acredite la interdicción o curaduría.

\section{Internamiento de personas con discapacidad psicosocial en centros psiquiátricos}

Como hemos señalado, en los últimos años, el entendimiento sobre la discapacidad ha cambiado a partir de la irrupción del modelo social de la discapacidad. Tal conceptualización no solamente es un esfuerzo académico, sino que tiene correspondencia con diferentes instrumentos normativos, como el artículo 12 de la CDPD. En la misma línea de que las personas con discapacidad tienen plena capacidad jurídica, el artículo 14 de la CDPD señala que los Estados deben asegurar que las personas con discapacidad "no se vean privadas de su libertad ilegal o arbitrariamente y que cualquier privación de libertad sea de conformidad con la ley, y que la existencia de una discapacidad no justifique en ningún caso una privación de la libertad”.

Determinar cuál es el alcance concreto de la prohibición sin duda no es tarea sencilla. A nivel del sistema universal de derechos humanos, no existe un 
acuerdo de si es posible o no internar contra su voluntad a una persona con discapacidad psicosocial. ${ }^{53}$ Aquí podrían plantearse dos grandes posiciones. ${ }^{54}$

La primera posición plantea que el internamiento involuntario de personas es permisible cuando se utilice como último recurso, siempre que sea necesario y proporcional. En este sentido se ha pronunciado, por ejemplo, el Comité de Derechos Humanos en su Observación General 35. El Comité señala que

...toda privación de libertad deberá ser necesaria y proporcional, con el propósito de impedir que el interesado se haga daño o cause lesiones a terceros. Deberá aplicarse solo como medida de último recurso y por el periodo de tiempo apropiado más breve posible; y deberá ir acompañada de garantías procesales y sustantivas adecuadas establecidas por ley. ${ }^{55}$

A juicio del Comité, ésta sería una restricción proporcional de los derechos de una persona con discapacidad consagrados en la CDPD frente a una amenaza a la vida o salud. ${ }^{56}$

La segunda posición, asumida por el Comité sobre los Derechos de las Personas con Discapacidad, señala que, siguiendo la literalidad del artículo 14 , una persona con discapacidad jamás podría ser internada involuntariamente, pues el internamiento siempre tendrá base en la discapacidad. ${ }^{57} \mathrm{~A}$ juicio del Comité, permitir el internamiento bajo coerción sería una forma desproporcionada de proteger los derechos de las personas con discapacidad intelectual. ${ }^{58}$ Esta posición también ha sido recogida por la doctrina en materia de discapacidad, cuyos autores señalan que el artículo 14 de la

53 Wayne, Martin y Gurbai, Sandor, Surveying the Geneva Impasse: Coercive Care and Human Rights", International Journal of Law and Psychiatry, vol. 64, 2019, p. 117, disponible en: https: / /doi.org/10.1016/j.ijlp.2019.03.001.

54 Para un estudio más detallado de estas posiciones, véase Gurbai, Sandor y Martin, Wayne, Is Involuntary Placement and Non-Consensual Treatment Ever Compliant with UN Human Rights Standards? A Survey of UN Reports (2006-2017), Essex, Essex Autonomy Project, 2018.

55 Comité sobre los Derechos Humanos, Observación general No. 35: Artículo 9 (Libertad y seguridad personales), CCPR/C/GC/35, 2015, párr. 19.

56 Wayne, Martin y Gurbai, Sandor, op. cit., pp. 120 y 121.

57 Comité sobre los Derechos de las Personas con Discapacidad, "Guidelines on article 14 of the Convention on the Rights of Persons with Disabilities. The right to liberty and security of persons with disabilities”, 2015, párrs. 6-10.

58 Wayne, Martin y Gurbai, Sandor, op. cit., p. 120. 
CDPD supone una prohibición de todo tipo de internamiento que haya sido rechazado por una persona con discapacidad.

En el ordenamiento jurídico peruano la LGPCD indica en su artículo 10 que: "Nadie puede ser privado de su libertad en razón de discapacidad". Las normas en materia de salud se alinean a la primera posición. El artículo 11 de la Ley 26842, Ley General de Salud (modificada por Ley 29889 y Ley 30947) indica que "el tratamiento e internamiento se realizan con el consentimiento informado, libre y voluntario del usuario, salvo en situaciones de emergencia”. Asimismo, establece que el internamiento será válido solo si se observan una serie de garantías formales, incluyendo la incorporación de una segunda opinión médica previa al internamiento, la duración de éste por el tiempo estrictamente necesario, y la revisión médica periódica de los diagnósticos e informes que recomiendan el internamiento (artículo 11). En adición a ello, la reciente Ley 30947, Ley de Salud Mental de 2019, establece que para que sea válido un internamiento involuntario, éste debe darse solo si existe un riesgo para la propia persona con discapacidad o para terceros, y debe tener una duración máxima de doce horas (artículo 5o., inciso 3).

En una línea similar, el Tribunal Constitucional peruano ha señalado que la restricción la libertad a una persona con discapacidad psicosocial debe ser excepcional, y debe darse solo si busca "garantizar la seguridad de dicha persona o de terceros". ${ }^{59}$ Además, ésto solo será posible "en tanto se establezcan las garantías procesales y sustantivas adecuadas, siempre respetando la dignidad de la persona (como ultima ratio, siempre que sea una medida legal y no arbitraria, en un centro de salud especializado, y esté sujeta a revisión periódica por la autoridad competente)" ${ }^{" 60}$. Cuando esas condiciones no se presenten, "está proscrita la posibilidad de restringir o privar del goce efectivo del derecho a la libertad personal a las personas con discapacidad únicamente por motivos de discapacidad, sea que se trate de una discapacidad real o una percibida". ${ }^{61}$

Pese a este marco normativo, hemos tomado conocimiento de que las personas con discapacidad psicosocial reconocidas como refugiados/as han

59 Tribunal Constitucional del Perú, Sentencia recaída en el Exp. 00194-2014-PHC/TC, 2019, párr. 58

60 Ibidem, párr. 60.ii.

61 Ibidem, párr. 60.i. 
sido enviadas, en la mayoría de los casos, al Hospital Víctor Larco Herrera (un centro psiquiátrico ubicado en Lima). ${ }^{62}$ En efecto, en respuesta a la solicitud de acceso a la información pública núm. 473-2019, el Ministerio de Relaciones Exteriores señala que tiene una práctica de derivación de personas con discapacidad psicosocial a instituciones psiquiátricas, como el Instituto Nacional de Salud Mental "Honorio Delgado-Hideyo Noguchi” y el Hospital Cayetano Heredia en aras de "buscar su estabilización”.

Esta práctica se viene implementando de conformidad con el Protocolo de Atención en Salud Mental para Solicitantes de Refugio en el Perú de la Comisión Especial para los Refugiados, remitido en respuesta a la solicitud de acceso a la información pública núm. 473-2019. Desde un inicio, se puede identificar una clara ausencia de un enfoque de discapacidad en este Protocolo, pues el marco legal del mismo omite referirse a la CDPD, la LGPD y su Reglamento, y la Ley General de Salud. Esto es preocupante cuando son precisamente estas normas las que establecen los requisitos y, aún más importante, las garantías aplicables al internamiento de personas con discapacidad psicosocial. Ahora bien, debemos reconocer que el Protocolo está pensando en un universo más amplio de solicitantes de refugio que requieran atención en salud mental — no solo en personas con discapacidad. Aun así, el documento se limita a establecer la necesidad de implementar canales de atención entre la CEPR y el Hospital Víctor Larco Herrera, en virtud de los cuales se derivan los casos de solicitantes de refugio "que necesiten una atención psiquiátrica, ya sea de emergencia o seguimiento". ${ }^{63}$

El Protocolo remitido no establece criterios de derivación, garantías de protección a la persona con discapacidad ni mecanismos de seguimiento. Esto resulta preocupante, pues implica que existe un espacio sumamente grande de desprotección una vez que la persona que requiere atención en salud mental es enviada al centro psiquiátrico. Además de ello, es notable la ausencia absoluta de referencias al consentimiento informado de la persona con discapacidad que es derivada a un centro psiquiátrico. En efecto, hemos tomado conocimiento de que varios solicitantes de refugio con discapacidad psicosocial han sido enviados al Hospital Víctor Larco Herrera. ${ }^{64}$

62 Información proporcionada de manera confidencial por los informantes 3 y 4.

63 Respuesta a solicitud de acceso a la información pública núm. 473-2019, pp. 3 y 4.

64 Información proporcionada de manera confidencial por el informante 3. 
La ausencia de garantías del Protocolo, combinada con la práctica y la falta de delimitación de un estándar claro que permita identificar cuando una persona requiere una atención de emergencia, no solamente demuestra una falta de sensibilización a los riesgos que enfrentan las personas con discapacidad psicosocial, sino que genera un espacio en el cual estas personas pueden ser víctimas de diversas violaciones de sus derechos humanos. La situación es particularmente preocupante pues no solo se actúa de oficio, sin una evaluación clara, sino además se señala que la mayoría de personas con discapacidad psicosocial han llegado a Perú solas. ${ }^{65}$ Esto resulta inválido a la luz, tanto del estándar nacional como internacional; además, resulta paradójico que se piense que una persona que ha atravesado medio continente sola no tenga claridad respecto de su deseo de residir y movilizarse en un país, y de recibir tratamiento médico o no. Finalmente, el internamiento implica un amplio espacio de riesgo, pues las personas con discapacidad psicosocial no tendrán un contacto externo con quien comunicarse si es que son víctimas de maltrato al interior del establecimiento.

\section{Acceso a servicios públicos}

Una vez que ingresan al país, las personas migrantes y refugiadas con discapacidad indican tener dificultades para acceder a una variedad de servicios públicos, en particular educación y salud. En materia educativa, se enfrentarán a barreras en el acceso y permanencia, dada la falta de escuelas inclusivas. En materia de salud, los migrantes con discapacidad muchas veces requieren atención pronta a causa del impacto adverso del viaje sobre su salud.

En educación, a nivel comparado, los estudios de campo han identificado que la mayoría de niños/as con discapacidad enfrentan barreras en el acceso a la educación regular. ${ }^{66}$ Cuando los niños/as migrantes y refugiados logran acceder a servicios educativos, en contextos de emergencia, estos generalmente no tienen estructuras ni materiales educativos accesibles. ${ }^{67}$ Adicionalmente,

65 Información proporcionada de manera confidencial por el informante 1.

66 Smith-Khan, Laura, "Overcoming Barriers to Education for Refugees with Disabilities", Legal Studies Research, paper No. 13/31, Sydney, The University of Sydney, 2013, p. 5, disponible en: https://bit.ly/3bcSryF.

67 Ibidem, p. 6. 
tienen dificultades para integrarse en el proceso educativo y recibir una educación de calidad, pues los docentes no están capacitados en educación inclusiva, ni en la atención específica que requieren niños/as y adolescentes que han pasado por un proceso de migración en contextos de emergencia. ${ }^{68}$

Al 2018, la Encuesta Dirigida a la Población Venezolana que Reside en el País, del Instituto Nacional de Estadística e Informática (INEI) de Perú, identificó que 23 mil alumnos de nacionalidad venezolana están integrados en el sistema de educación pública. ${ }^{69}$ Estos niños/as y adolescentes migrantes ya enfrentan prejuicios a causa de su discapacidad, ${ }^{70}$ agravados por la ausencia de planes de convivencia escolar en $42 \%$ de las escuelas públicas y privadas. ${ }^{71}$ Muchos de ellos/as han sido víctimas de bullying en sus escuelas. Según el relato de un usuario de la Clínica Jurídica, los estudiantes del colegio de su hija la agredían haciéndole heridas con lápices durante las sesiones de clase.

A ello se suman los prejuicios y falta de capacitación del personal de los colegios frente a la migración y la discapacidad. De conformidad con el artículo 23 de la LGPD y la Resolución Ministerial 665-2018-MINEDU, Norma que regula la matrícula escolar y traslado en las instituciones educativas y programas de educación básica, los colegios públicos deben reservar dos vacantes por aula para estudiantes con discapacidad leve o moderada. En diversas ocasiones, el personal directivo de distintos colegios ha manifestado a padres de niños/as migrantes con discapacidad que no restan vacantes reservadas en la escuela, aun cuando esta información era falsa. Adicionalmente, los estudiantes que logran acceder a una vacante se enfrentan a las mismas barreras propias de la discapacidad — falta de accesibilidad en las escuelas, y la falta de apoyos para educación. ${ }^{72}$

68 Idem.

69 Belapatiño, Vanessa et al., "Inmigración venezolana a Perú: características e impactos macroeconómicos”, BBVA Research, 10 de octubre de 2019, p. 17, disponible en: https: / / bit. ly $/ 2$ YBPRPV.

70 Vadillo Villa, José, Niños venezolanos en Perú, su integración es una tarea pendiente, Andina, 13 de septiembre de 2019, disponible en: https: / / bit.ly/35BNcr4.

71 "Más del 40\% de centros educativos en zonas urbanas no tienen planes para combatir el bullying”, Defensoría del Pueblo, 2 de mayo de 2019, disponible en: https: / / bit.1y/35CESXT.

72 Constantino Caycho, Renato, Al final del salón: un diagnóstico de la situación de la educación de personas con discapacidad en el Perú, Lima, Paz y Esperanza, 2016, pp. 60-64 y 69-71, disponible en: https: / / bit.ly/2zgqadl. 
Esta revista forma parte del acervo de la Biblioteca Jurídica Virtual del Instituto de Investigaciones Jurídicas de la UNAM

En relación con el derecho a la salud, estudios anteriores se ha encontrado que los migrantes y refugiados con discapacidad no pueden acceder a servicios de apoyo psicosocial, terapias y otros servicios especializados en contextos de emergencia. ${ }^{73}$ Adicionalmente, cuando estos sí están disponibles, no suelen ser accesibles en términos físicos y económicos, y omiten proveer información accesible a los pacientes. ${ }^{74} \mathrm{Si}$ las personas con discapacidad logran acceder a servicios de salud, usualmente se enfrentan a personal que no está adecuadamente capacitado, y frecuentemente tiene prejuicios frente a la población migrante con discapacidad. ${ }^{75}$

En Perú, la Encuesta Dirigida a la Población Venezolana que Reside en el País señala que de las personas migrantes y refugiadas venezolanas que tenían enfermedades crónicas en 2018, 78\% no recibió tratamiento médico. ${ }^{76}$ De acuerdo con el Ministerio de Salud, no existe ninguna política ni programa de atención en salud para refugiados y migrantes con discapacidad. ${ }^{77}$ En razón de ello, se aplican los requisitos regulares para la atención en salud, aun cuando los migrantes con discapacidad se encuentran en una situación de mayor urgencia.

Esto implica, en primer lugar, que se requiere contar con documentación que acredite la calidad migratoria, aun cuando la recepción de estos documentos tiene un retraso significativo. Esto significa que una persona

73 Reilly, Rachael, "Disabilities among Refugees and Conflict-Affected Populations", Forced Migration Review, vol. 35, 2010, pp. 8-10, disponible en: https://bit.ly/2We4Chi 2010; Humanity and Inclusion e iMMAP, "Removing Barriers. The Path towards Inclusive Access. Disability Assessment among Syrian Refugees in Jordan and Lebanon”, 2018; Handicap International y HelpAge International, Hidden Victims of the Syrian Crisis: Disabled, Injured and Older Refugees, International Committee of the Red Cross-UNICEF, 2014, disponible en: https:// bit.ly/2 WbbMMo.

74 Humanity and Inclusion e iMMAP, op. cit.; Handicap International y HelpAge International, op. cit.; Owiny, Eunice y Naguija, Yusra, "Caught between a Rock and a Hard Place: Challenges of Refugees with Disabilities and their Families in Uganda”, Refugee Law Project, 2014, disponible en: https: / / bit.ly/35GSn97.

75 Reilly, Rachael, op. cit.; Humanity and Inclusion e iMMAP, op. cit.; Handicap International y HelpAge International, op. cit.; Tanabe, Mihoko et al., "Intersecting Sexual and Reproductive Health and Disability in Humanitarian Settings: Risks, Needs, and Capacities of Refugees with Disabilities in Kenya, Nepal, and Uganda”, Sexuality and Disability, vol. 33, núm. 4, 2015, pp. 411-427, disponible en: https: / /bit.ly/2yCV6ZY.

76 Belapatiño, Vanessa et al., op. cit., p. 20.

77 Esta información fue proporcionada en respuesta a la solicitud de acceso a la información pública núm. 10-009689 remitida por las autoras al Ministerio de Salud. 
con discapacidad podría tener que esperar mucho tiempo para acceder al sistema de salud, aun si tuviese necesidades urgentes.

En segundo lugar, dada la falta de capacidad de atención de los centros de salud pública, y los altos costos de los servicios de salud privados, los/ as migrantes con discapacidad no pueden acceder a servicios de ayuda psicosocial, terapia y servicios especializados. Esto, sumado a la falta de documentos para acceder a prestaciones públicas en salud, limita las alternativas de atención en salud que tienen las personas bajo calidades migratorias especiales. En efecto, el propio Ministerio de Salud reconoce que no existen normas o programas de atención a migrantes bajo estas calidades migratorias, pero que existen algunos programas estatales que brindan atención universal y gratuita en salud. Los programas mencionados se limitan al control del VIH/SIDA, de la tuberculosis, la nutrición, y a la inmunización. ${ }^{78}$ Estas prestaciones difícilmente resultan suficientes para atender el universo de necesidades que tiene el colectivo de personas con discapacidad. Es menester recalcar que, en respuesta a esta situación, diversas organizaciones no-gubernamentales han facilitado fondos para que los migrantes puedan atenderse en hospitales públicos o privados.

Adicionalmente, es particularmente preocupante la exigencia de requisitos burocráticos para la emisión del certificado de discapacidad. Éste es fundamental para acceder a una serie de beneficios diseñados para personas con discapacidad. Por ende, resulta preocupante que la Norma Técnica de Salud NTS 127-2016/MINSA/DGIESP exija la presentación del Documento Nacional de Identidad o Carné de Extranjería para otorgar un certificado de discapacidad. En atención a esta situación, el Ministerio de Salud informa que se han brindado certificados de discapacidad temporales y con custodia física en los establecimientos médicos a personas que cuentan con PTP. ${ }^{79} \mathrm{Si}$ bien esta medida es positiva, aun excluye a una cantidad significativa de personas con discapacidad, especialmente si se toma en cuenta que las autoridades ya no emiten el PTP.

Finalmente, aun cuando las personas con discapacidad logran recibir atención médica, enfrentan barreras en la atención. Por un lado, según testimonios de personas migrantes, cuando tienen una discapacidad que requiere un tratamiento médico muchas veces no pueden cubrir el gasto de

78 Idem.

79 Idem. 
dicho tratamiento, pues no pueden acceder a oportunidades laborales estables. Por otro lado, los testimonios de funcionarios y de migrantes demuestran que el personal de establecimientos de salud, en muchas ocasiones, no está capacitado para tratar con personas con discapacidad ni personas extranjera. Por ello, se han identificado episodios de xenofobia y rechazo al brindar atención a médica a personas venezolanas, especialmente cuando estas se encuentran en situación de discapacidad. ${ }^{80}$

\section{Falta de información estadística}

En virtud del artículo 31 de la CDPD, los Estados debe recopilar "información adecuada, incluidos datos estadísticos y de investigación, que les permita formular y aplicar políticas, a fin de dar efecto a la presente Convención". En términos generales, la CDPD establece que la información debe garantizar la protección de datos en esta recopilación y debe proporcionar información accesible a personas con discapacidad (artículos 31 y 35). Ahora bien, esta obligación no debe ser leída sólo en abstracto, sino también en relación con los flujos migratorios de los Estados.

En Perú, un problema trasversal a todas las categorías migratorias es la falta de un registro adecuado de la discapacidad en los sistemas migratorios. Además de satisfacer la obligación de recopilar información estadística establecida en la CDPD, el registro de información sobre migrantes y refugiados es fundamental para aquellas personas en situación de riesgo y aquellas con necesidades específicas, pues solo de esta manera se puede asegurar que reciban la asistencia necesaria y adecuada ${ }^{81}$ Esto es particularmente importante en el caso de personas con discapacidad, pues contar con información inexacta genera brechas entre las necesidades reales y la asistencia provista por el Estado.

Actualmente, la mayoría de discapacidades son catalogadas como "no especificadas", y los sistemas de registro del Estado impiden consignar la multidiscapacidad. Incluso, en algunos casos, los/as refugiados/as con discapacidades leves pueden no ser catalogados como refugiados/as con discapacidad. Esto

80 Información proporcionada de manera confidencial por el informante 1.

81 ACNUR. UNHCR Handbook for Registration. Procedures and Standards for Registration, Population Data Management and Documentation, Ginebra, ACNUR, 2003, p. 7. 
resulta problemático, pues sin datos exactos sobre los tipos de discapacidad que tienen las personas migrantes y refugiadas, difícilmente se pueden diseñar políticas y programas de atención que presten una asistencia efectiva. Por otro lado, las falencias en el registro llevan a una clara ausencia de estadísticas sobre migrantes y refugiados con discapacidad. Esto es evidente en los informes citados al inicio de este trabajo, en los que es notable la ausencia de información estatal.

Teniendo esto en cuenta, resulta necesario que las instituciones del Estado peruano cuenten con mecanismos de registro y recopilación de estadísticas adecuados, específicamente diseñados para personas con discapacidad. ${ }^{82}$ Además, resulta necesario que todo sistema de registro considere la multidiscapacidad y disgregue la información recopilada por edad y sexo. ${ }^{83}$

\section{CONCLUSIONES}

En los últimos años, Perú ha experimentado un flujo migratorio masivo e inesperado. Esto, sin duda, presenta una serie de retos a dichas instituciones. Atender las necesidades de la población migrante significa, también, reconocer el impacto diferenciado que tiene la migración sobre ellas. Es fundamental que un enfoque de discapacidad sea transversal a todas las acciones del Estado. De lo contrario, no se otorga una protección adecuada a un colectivo que enfrenta una situación de vulnerabilidad agravada por la migración. Por ello, este documento ha buscado identificar situaciones en las cuáles resulta particularmente importante adoptar un enfoque de discapacidad.

Habiendo analizado el statu quo en el ordenamiento peruano, es claro que queda un largo camino por recorrer para incorporar un enfoque de discapacidad a las políticas y prácticas migratorias. En particular, es funda-

82 ACNUR, El trabajo con personas con discapacidad durante el desplazamiento forzado, Ginebra, ACNUR, 2011, pp. 10-13, disponible en: https://www.acnur.org/fileadmin/Documentos/ BDL/2011/7646.pdf; ACNUR, Conclusión general..., cit.; Women’s Refugee Commission, Disabilities among Refugees and Conflict Affected Populations, Nueva York, Women's Refugee Commission, 2008, p. 5.

83 Women's Refugee Commission, op. cit., p. 5. 
mental revisar las formas de acceder a diversas calidades migratorias desde la perspectiva del migrante con discapacidad. Además, es necesario que se revisen las prácticas de atención a personas con discapacidad psicosocial, de manera que estas se alineen a los estándares internacionales y nacionales en la materia, y resulten verdaderamente garantistas. También será importante atender a las necesidades de migrantes y refugiados con discapacidad en el acceso a todos los servicios públicos, no solo educación y salud. Finalmente, es trascendental contar con mayor información sobre la situación de personas migrantes y refugiadas con discapacidad en el país. Sin esta, difícilmente se podrán conocer con certeza los alcances del problema y proponer soluciones efectivas.

\section{BIBLIOGRAFÍA}

ACNUR e InTER-PARliamentary Union, A Guide to International Refugee Protection and Building State Asylum Systems. Handbook for Parliamentarians $N^{\circ} 27$, Ginebra, Inter-Parliamentary Union-United Nations High Commissioner for Refugees, 2017.

ACNUR, "Informe Semestral del Monitoreo de Protección en Perú", Lima, 2019, disponible en: https: / / bit.ly/2WeFsIg.

ACNUR, "Mechanisms for Screening and Referral, The 10 Point Plan in Action", 2016, disponible en: https://bit.ly/3dpk6xD.

ACNUR, "Monitero de Protección. Mayo-Junio 2019”, Lima, 2019, disponible en: https: / /data2.unhcr.org/en / documents / details / 70520.

ACNUR, "Perú", 2019, disponible en: https: / / www.acnur.org/peru.html.

ACNUR, El trabajo con personas con discapacidad durante el desplazamiento forzado, Ginebra, ACNUR, 2011, disponible en: https: / /www.acnur.org/filea dmin /Documentos/BDL/2011/7646.pdf.

ACNUR, Manual de procedimientos y criterios para determinar la condición de refugiado en virtud de la Convención de 1951 y el Protocolo de 1967 sobre el Estatuto de los Refugiados, Ginebra, ACNUR, 2019.

ACNUR, UNHCR Handbook for Registration. Procedures and Standards for Registration, Population Data Management and Documentation, Ginebra, ACNUR, 2003. 
AdDAney, Michal et al., "Legal Capacity of and Access to Justice for Refugees with Disabilities in Africa”, De Jure Law Journal, vol 52, núm. 1, 2019, pp. 335-357, diponible en: http://www.scielo.org.za/scielo.php ?script $=$ sci_arttext\&pid=S2225-71602019000100020.

AYLWARD, Carol, "Intersectionality: Crossing the Theoretical and Praxis Divide”. Journal of Critical Race Inquiry, vol. 1, núm. 1, 2010, disponible en: https://doi.org/10.24908/jcri.v1i1.3549.

BELAPATIÑO, Vanessa et al., "Inmigración venezolana a Perú: características e impactos macroeconómicos”, BBVA Research, 10 de octubre de 2019, disponible en: https: / /bit.ly/2YBPRPV.

BLOUIN, Cécile, "Entrevista sobre la migración venezolana y visa humanitaria”, Enfoque Derecho, 21 de junio 2019, disponible en: https: / bit. $1 y / 31 w j E 5 w$.

BREGAGLIO, Renata, "El principio de no discriminación por motivo de discapacidad”, en Bregaglio, Renata y SAlmón, Elizabeth (eds.), Nueve conceptos clave para entender la Convención sobre los Derechos de las Personas con Discapacidad, Lima, IDEHPUCP, 2014.

BRognA, Patricia, "La representaciones de la discapacidad: la vigencia del pasado en las estructuras sociales presentes”, Visiones y revisiones de la discapacidad, México, Fondo de Cultura Económica.

"Cancillería: capacidad del Estado para atender el incremento de la migración venezolana ha sido sobrepasada”, El Comercio, 29 de octubre de 2019, disponible en: https://bit.ly/3fkM4fU.

CAmino, Paula. Riesgos invisibilizados: La necesidad de una directiva de atención a refugiados y refugiadas con discapacidad (tesina para optar por el grado Bachiller en Derecho), Lima, Pontificia Universidad Católica del Perú, 2020, disponible en: https: / / bit.ly / 2 WCQIgH.

Constantino CAycho, Renato, Al final del salón: un diagnóstico de la situación de la educación de personas con discapacidad en el Perú, Lima, Paz y Esperanza, disponible en: 2016, https: / bit.ly/2zgqadl.

Constantino Caycho, Renato y Galicia Vidal, Saulo, "La configuración de los ajustes razonables en el ámbito laboral peruano: definiciones, omisiones y propuestas", Anuario de Investigación del CICAJ 2013-2014, 2015, disponible en: https: / /bit.ly/2 WbiodI.

CRenshaw, Kimberlé, "Mapping the Margins: Interseccionality, Identity Politcs and Violence Against Women of Color", en CRENSHAW et al. 
Esta revista forma parte del acervo de la Biblioteca Jurídica Virtual del Instituto de Investigaciones Jurídicas de la UNAM

(eds.), Critical Race Theory. The KeyWritings that Formed the Movement, NuevaYork, The New Press, 1995.

CROCK, Mary et al. "Where Disability and Displacement Intersect: Asylum Seekers and Refugees with Disabilities", International Journal of Refugee Law, vol. 24, núm. 4, 2013, disponible en: https: / / bit.ly/2L60wuc.

GuRBAI, Sandor y MARTIN, Wayne, Is Involuntary Placement and Non-Consensual Treatment Ever Compliant with UN Human Rights Standards? A Survey of UN Reports (2006-2017), Essex, Essex Autonomy Project, 2018.

HANDICAP INTERNATIONAL y HELPAGE INTERNATIONAL, HiddenVictims of the Syrian Crisis: Disabled, Injured and Older Refugees, International Committee of the Red Cross-UNICEF, 2014, disponible en: https: / / bit.ly / 2 WbbMMo.

HUMANITY AND INCLUSION e IMMAP, "Removing Barriers. The Path towards Inclusive Access. Disability Assessment among Syrian Refugees in Jordan and Lebanon”, 2018.

"Más del 40\% de centros educativos en zonas urbanas no tienen planes para combatir el bullying”, Defensoría del Pueblo, 2 de mayo de 2019, disponible en: https: / / bit.ly/35CESXT.

Minkowitz, Tina, "Abolishing Mental Health Laws to Comply with the Convention on the Rights of Persons with Disabilities", en MCSHERRY, B., y Weller, P. (eds.), Rethinking Rights-Based Mental Health Laws, Portland, Hart Publishing, 2010.

OIM y ACNUR, "Monitoreo de flujo de población venezolana en el Perú", DTM Ronda 5, Lima, 2019, disponible en: https: / / bit.ly/3dx4Fnt.

OWInY, Eunice y NaguijA, Yusra, "Caught between a Rock and a Hard Place: Challenges of Refugees with Disabilities and their Families in Uganda”, Refugee Law Project, 2014, disponible en: https: / / bit.ly/35GSn97.

Palacios, Agustina, El modelo social de discapacidad. Orígenes, caracterización y plasmación en la Convención Internacional sobre los Derechos de las Personas con Discapacidad, Madrid, Cinca, 2008.

PALACIOS, Agustina y BARIFFI, Francisco, La discapacidad como una cuestión de derechos humanos. Una aproximación a la Convención Internacional sobre los Derechos de las Personas con Discapacidad, Madrid, Cinca, 2014, disponible en: https: / / bit.ly/2A16qKT.

REILly, Rachael, "Disabilities among Refugees and Conflict-Affected Populations", Forced Migration Review, vol. 35, 2010, disponible en: https: / / bit.ly/2We4Chi. 
SHIVJI, Aleema, "Disability in Displacement", Forced Migration Review, 2010, disponible en: https://bit.ly/2WdiJMT.

SMITH-KHAN, Laura, "Overcoming Barriers to Education for Refugees with Disabilities”, Legal Studies Research, paper No. 13/31, Sydney, The University of Sydney, 2013, disponible en: https: / / bit.ly/3bcSryF.

TANABE, Mihoko et al., "Intersecting Sexual and Reproductive Health and Disability in Humanitarian Settings: Risks, Needs, and Capacities of Refugees with Disabilities in Kenya, Nepal, and Uganda", Sexuality and Disability, vol. 33, núm. 4, 2015, disponible en: https: / / bit.ly /2y $C_{v} 6 Z Y$.

Treneman, Alvaro, “¡Alarmante! En el Perú solo existen 1082 psiquiatras de los cuales solo cinco se especializan en adicciones”, Perú 21, 20 de noviembre de 2019, disponible en: https: / /bit.ly/3dCZwu7.

VADillo VILA, José, Niños venezolanos en Perú, su integración es una tarea pendiente, Andina, 13 de septiembre de 2019, disponible en: https://bit.ly/ $35 B N_{c r} 4$.

Wayne, Martin y GuRbaI, Sandor, "Surveying the Geneva Impasse: Coercive Care and Human Rights", International Journal of Law and Psychiatry, vol. 64, 2019, disponible en: https: / / doi.org/10.1016/j.ijlp.2019.03.001.

Women's Refugee Commission, Disabilities among Refugees and Conflict Affected Populations, Nueva York, Women's Refugee Commission, 2008. 